\title{
The atheroprotective effects of genistein in hypercholestrolemic male rabbit
}

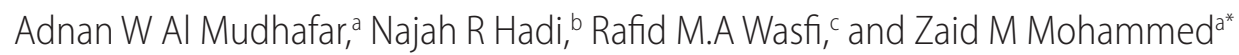

\author{
aDepartment of Food Science, College of Agriculture, Kufa University, Iraq. \\ bDepartment of Pharmacology and Therapeutics, College of Medicine, Kufa University, Iraq. \\ 'Department of Clinical Pharmacy, College of Pharmacy, Kufa University, Iraq. \\ *Correspondence to Zaid M Mohammed (email: zaidmahdi13@yahoo.com). \\ (Submitted: 10 September 2018 - Revised version received: 18 September 2018 - Accepted: 06 December 2018 - Published online:26 December 2018)
}

\begin{abstract}
Objective The occurrence of this disease is related to different risk factors such as cardiovascular issues and elevated levels of plasma cholesterol, hypertension, diabetes mellitus and many others.

Methods Three groups of domestic male rabbits, six in each group, were studied. Each group constituted a different diet condition where group I had a normal chow diet; group II a 1\% cholesterol-diet, group III a 1\% cholesterol-diet and Genistein. The level of serum total cholesterol (TC), triglycerides (TG) and High density lipoprotein HDL-C serum interleukin-6 (IL-6), serum high sensitive C-reactive protein (hs-CRP), serum monocyte chemo-attractant protein type 1 High mobility group box 1 (MCP-1) and HMG-box 1 was monitored by collecting blood samples at the start of the study, 28 and 56 days. Then, the aorta was removed to be examined (histopathology) for atherosclerosis lesion and thickening in the aortic intima-media.

Results In comparison to the control group (I), levels of TC, TG, low-density lipoprotein (LDL) cholestrol, very LDL cholestrol, hs-CRP, IL-6, MCP-1 and HMG-box 1 had increased while serum HDL-C had reduced in the animals that followed a high-fat diet. Histologically, the aortic intimal thickening and atherosclerosis lesions has increased in the induced-untreated animals. The Genistein treated group showed a substantial decrease of lipid parameters in comparison with the induced-untreated group. Genistein counteracted the changes in hs-CRP, IL-6, MCP-1 and HMG-box 1 in compared with the induced-untreated group $(P<0.05)$. Histomorphometric measurements indicated that Genistein significantly minimizes the thickness of the aortic intima-media and atherosclerosis lesions in comparison to the animals on a high-fat diet.

Conclusion The outcomes of this investigation show that Genistein significantly decrease the progression of atherosclerosis in hypercholesterolemic animals via inhibition of inflammatory markers and reduced levels of lipid parameters.

Keywords genistein, atherosclerosis, inflammation
\end{abstract}

\section{Introduction}

Atherosclerosis is a serious, chronic inflammatory disease where arteries become clogged with lipids (plaques or atheroma). ${ }^{1}$ It begins with the accumulation of fatty substances in the arteries, this leading to the hardening and narrowing of said arteries. ${ }^{2}$ The initial step in the pathogenesis of atherosclerosis is the lipid retention followed by chronic inflammation at sensitive sites in the major walls of arteries, this resulting in fatty streaks, which then develop into fibroatheromas. ${ }^{3,4}$ Endothelial dysfunction indicates the start of this process.

A variety of mediators induce endothelial dysfunction, some of which are currently unknown, others known and related to established cardiovascular risk factors such as dyslipidemia, smoking, diabetes mellitus, aging and hypertension. ${ }^{5}$ Other risk factors also contribute, for example lipids in the blood, low-density lipoprotein (LDL) and very LDL (VLDL) bind to endothelial cells and oxidize in the subendothelial space. $\mathrm{T}$ cells and monocytes bind to the endothelial cells and migrate to the subendothelial space, where monocytes engulf the oxidized LDL and transformed into foam cells. This process represents the first stage after which macrophages further elaborate proinflammatory cytokines that recruit smooth muscle cells, this producing an increase in smooth muscle cells and replication in dense extracellular matrix. The resulting atherosclerosis lesion is a subendothelial fibrous plaque composed of a lipid core surrounded by connective tissue fibers and smooth muscle cells. ${ }^{6}$ Normal adaptive vascular responses, such as the release of endothelium-derived $\mathrm{NO}$, are subsequently impaired. Endothelial activation results in inflammatory cells and the adhesion of platelets that can release proatherogenic growth factors. These factors result in the migration and proliferation of vascular smooth muscle cells (VSMCs) and the increased generation of extracellular matrix. Lymphocytes and monocytes invade the vessel walls, contributing to the processes of inflammation that results in atherosclerosis lesion formation. Forms of (LDL) cholesterol that accumulate in the vessel walls, may be taken up by macrophages and other vascular cells, resulting in foam cell formation. ${ }^{7,8}$

Inflammation plays an important role in plaque initiation, disruption and progression. Levels of C-reactive protein (CRP), an acute phase protein released from the liver in response to infection or inflammation, is a predictor of cardiovascular events. ${ }^{9,10}$ Various forms of vascular injury, including elevated levels of modified (LDL), stimulate proinflammatory effects resulting in the recruitment of T lymphocytes and monocytes, the earliest feature of atherosclerosis lesion formation. ${ }^{11}$ This infiltration by inflammatory cells is mediated by various chemokines including interleukins (IL) and monocyte chemo-attractant protein type 1 (MCP-1). ${ }^{12}$ These monocytes change into macrophages and up-regulate their scavenger receptor expression, allowing them to accumulate lipids which results in the formation of fatty streaks and foam cells. These activated macrophages release growth factors and numerous cytokines including tumor necrosis factor- $\alpha$, interleukins (IL, especially IL- $1 \beta$, IL- 6 and IL-8), and MCP-1. These factors, which can stimulate adhesion molecule expression, macrophage 
activation, leukocyte migration, VSMC proliferation and vascular permeability, are normally expressed in the vessel wall, but their concentrations are significantly higher in atherosclerosis plaque. ${ }^{13}$

A wide body of literature showed that Genistein, which is an isoflavone phytoestrogen, has a central role in the regulation of different biological activities, acting as an inhibitor for tyrosine kinase proteins. ${ }^{14}$ With this in mind, many researchers are investigating its potential action in the treatment of diseases such as the cancer, and its effect on skeletal and cardiovascular health. These investigations have focused on the potential hypolipidemic, anti-inflammatory, antioxidative and estrogenic effects of the Genistein..$^{15}$

\section{Materials and Methods}

Three groups of domestic male rabbits, six in each group, were studied, each under different conditions. Group I was the control group kept on a normal chow diet; group II was given a $1 \%$ of cholesterol-diet, group III a 1\% cholesterol-diet and Genistein. Levels of serum total cholesterol (TC), triglycerides (TG) and HDL-C serum IL-6, serum high sensitive CRP (hs-CRP), serum MCP-1 and serum HMG-boxl was monitored by collecting blood samples at the start of the study, 28 and 56 days. At the end of the experiment, the aorta was removed to be examined (histopathology) for atherosclerotic changes or changes in the thickness of aortic intima-media.

\section{Blood Sampling}

The sampling process involved taking $5 \mathrm{ml}$ of blood from the central ear artery of the rabbits following overnight fasting. Blood sampling was carried out at zero time, 28 and 56 days. The samples of blood were permitted to clot at $37^{\circ} \mathrm{C}$, then cene trifuged for $12 \mathrm{~min}$ at $6000 \mathrm{rpm}$. The isolated serum was analyzed to measure serums TC, TG, HDL-C, LDL-C, VLDL-C, IL-6 and CRP, HMG-box1, MCP-1.

\section{Tissue Sampling for Histopathology}

At the end of the experiment (56 days), the rabbits were euthanized using chloroform. Their chest walls were dissected for resection of the aorta. The removed connective tissue samples, after removal of adherent fat, were immediately fixed in a $10 \%$ xylene solution. Following fixation tissue sampling, the samples were processed in the usual method. Samples were observed with a microscope under a magnification power of $10 \times$ and $40 \times$, the histopathological alterations determined. Atheroscle $\epsilon$ rosis lesions were categorized into different phases as outlined by the American Heart Association classifications. $^{16}$

\section{Results}

\section{Influence of Genistein on Serum Lipid Profiles}

After 28 days, the results revealed a substantial increase in the lipid profile of the rabbits that followed a high cholesterol diet. Over the same period, the Genistein-treated rabbits showed a substantial decrease in serum lipids in comparison to the untreated rabbits (Table 1).

\section{Influence of Genistein on hs-CRP, IL-6 and MCP1}

According to the statistical analyses, at the beginning of the study, the groups of rabbits showed non-significant differences in levels of serum hs-CRP, IL- 6 and MCP-1. However, substantial differences $(P<0.05)$ in levels of hs-CRP, IL- 6 and MCP-1 were recorded after 28 days where a significant increase was noticed in the high cholesterol diet animals. After 56 days, the Genistein-treated rabbits showed a substantial decrease $(P<0.05)$ in the levels of hs-CRP, IL-6 and MCP-1 (Table 2).

\section{Influence of Genistein on HMG-box1}

Prior to the experiment, the levels of serum HMG-box1 in the rabbits, were statistically analyzed, the results showing non-significant differences. After 28 days, the high cholesterol diet group showed a substantial increase in HMG-box1 levels. After 56 days, the Genistein-treated rabbits showed a clear increase in the level of HMG-box1 (Table 3).

\section{Influence of Genistein on Aortic Intima-media Thickness}

After 56 days, the high cholesterol diet rabbits showed a clear increase in the thickness of the aortic intima-media, as shown in Figs. 1 and 2. The Genistein-treated rabbits had a lower thickening in the aortic intima-media (Figure 3 and Table 4).

Table 1. Influence of cholesterol-enriched diet and Genistein $10 \mathbf{m g} / \mathbf{k g} /$ day on serum lipid profile. Values are represented as means \pm SEM (Six rabbits in each group)

\begin{tabular}{|c|c|c|c|c|}
\hline & & $\mathrm{TC}(\mathrm{mg} / \mathrm{dl})$ & TG (mg/dl) & HDL (mg/dl) \\
\hline \multirow[t]{3}{*}{ Normal control } & Zero time & $48.8 \pm 3.0$ & $49.5 \pm 2.1$ & $21.0 \pm 1.7$ \\
\hline & 28 days & $47.0 \pm 3.8$ & $50.8 \pm 3.4$ & $20.1 \pm 1.5$ \\
\hline & 8 weeks & $46.5 \pm 2.4$ & $44.3 \pm 0.8$ & $21.5 \pm 0.8$ \\
\hline \multirow[t]{3}{*}{ Induced-untreated } & Zero time & $46.3 \pm 3.7$ & $57.3 \pm 1.8$ & $20.2 \pm 1.4$ \\
\hline & 28 days & $625.0 \pm 12.1^{*}$ & $123.7 \pm 17.8^{*}$ & $13.9 \pm 0.5^{*}$ \\
\hline & 8 weeks & $859.0 \pm 73.8^{+}$ & $172.0 \pm 6.7^{\dagger}$ & $12.0 \pm 0.2^{\dagger}$ \\
\hline \multirow[t]{3}{*}{ Genistein 10 mg/kg } & Zero time & $51.0 \pm 2.7$ & $51.5 \pm 1.8$ & $21.8 \pm 1.1$ \\
\hline & 28 days & $663.8 \pm 17.8^{*}$ & $138.5 \pm 17.0^{*}$ & $12.3 \pm 0.4^{*}$ \\
\hline & 8 weeks & $271.8 \pm 50.6^{\dagger}$ & $85.8 \pm 12.3^{\dagger}$ & $17.1 \pm 0.9^{\dagger}$ \\
\hline
\end{tabular}

${ }^{*}$ Means at 28 days significant to means at 0 days; ${ }^{\dagger}$ Means at 56 days means to averages at 28 days. 
Table 2. Influence of cholesterol-enriched diet and Genistein $10 \mathrm{mg} / \mathbf{k g} /$ day on serum inflammatory marker (hs-CRP, IL-6, MCP-1). Values are represented as means \pm SEM (Six rabbits in each group)

\begin{tabular}{|c|c|c|c|c|}
\hline & & hs-CRP mg/l & IL-6 pg/l & MCP-1 \\
\hline \multirow[t]{3}{*}{ Normal control } & Zero time & $3.0 \pm 0.2$ & $1.3 \pm 0.1$ & $0.7 \pm 0.1$ \\
\hline & 28 days & $3.4 \pm 0.1$ & $1.3 \pm 0.1$ & $1.0 \pm 0.1$ \\
\hline & 8 weeks & $3.3 \pm 0.2$ & $1.2 \pm 0.2$ & $0.7 \pm 0.1$ \\
\hline \multirow[t]{3}{*}{ Induced-untreated } & Zero time & $3.0 \pm 0.2$ & $1.5 \pm 0.3$ & $1.0 \pm 0.2$ \\
\hline & 28 days & $5.5 \pm 0.2^{*}$ & $4.7 \pm 0.3^{*}$ & $4.2 \pm 0.3^{*}$ \\
\hline & 8 weeks & $7.5 \pm 0.2^{\dagger}$ & $6.6 \pm 0.3^{\dagger}$ & $5.6 \pm 0.2^{\dagger}$ \\
\hline \multirow[t]{3}{*}{ Genistein 10 mg/kg } & Zero time & $3.1 \pm 0.1$ & $1.3 \pm 0.3$ & $1.2 \pm 0.2$ \\
\hline & 28 days & $6.1 \pm 0.3^{*}$ & $4.8 \pm 0.3^{*}$ & $4.6 \pm 0.2^{*}$ \\
\hline & 8 weeks & $5.3 \pm 0.3^{\dagger}$ & $2.5 \pm 0.4^{\dagger}$ & $1.6 \pm 0.1^{\dagger}$ \\
\hline
\end{tabular}

${ }^{*}$ Means at 28 days significant to means at 0 days, ${ }^{\dagger}$ Means at 56 days significant to means at 28 days.

\begin{tabular}{|c|c|c|}
\hline & & HMG-box1 \\
\hline \multirow[t]{3}{*}{ Normal control } & Zero time & $0.7 \pm 0.03$ \\
\hline & 28 days & $0.8 \pm 0.1$ \\
\hline & 8 weeks & $0.7 \pm 0.2$ \\
\hline \multirow[t]{3}{*}{ Induced-untreated } & Zero time & $0.8 \pm 0.1$ \\
\hline & 28 days & $2.9 \pm 0.04^{*}$ \\
\hline & 8 weeks & $4.1 \pm 0.09^{\dagger}$ \\
\hline \multirow[t]{3}{*}{ Genistein 10 mg/kg } & Zero time & $0.7 \pm 0.6$ \\
\hline & 28 days & $3.8 \pm 0.08^{*}$ \\
\hline & 8 weeks & $1.9 \pm 0.4^{\dagger}$ \\
\hline
\end{tabular}

"Means at 28 days significant to means at 0 days; ${ }^{\dagger}$ Means at 56 days significant to means at 28 days.

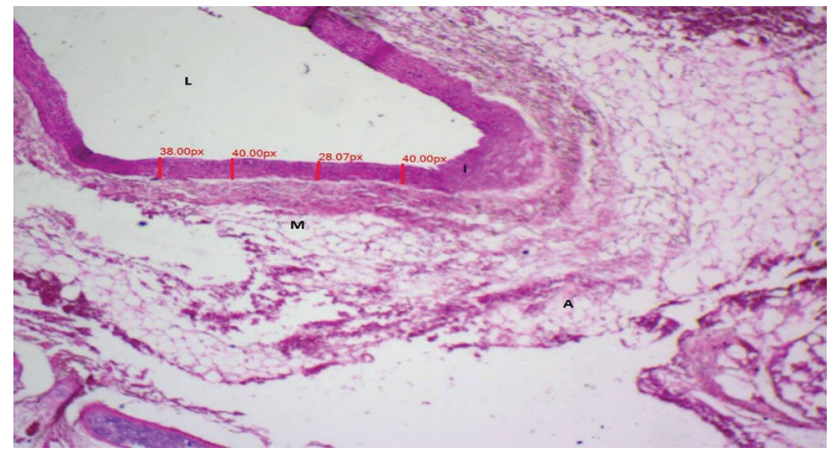

Fig. 1 Photomicrograph of histophotometric section in aortic arch of rabbit fed on normal diet for 8 weeks (normal control) show the normal intimal thickness and intact continuous endothelium. Stained with haematoxylin and Eosin (10X), where, I: intima of the aorta, M: media of the aorta, A: adventitia of the aorta and L: the lumen of the aorta.

\section{Discussion}

The outcome of the current study reveals a direct relationship between a cholesterol-enriched diet and serum TC, TG, LDL-C, VLDL levels, where a clear increase has been noted in these

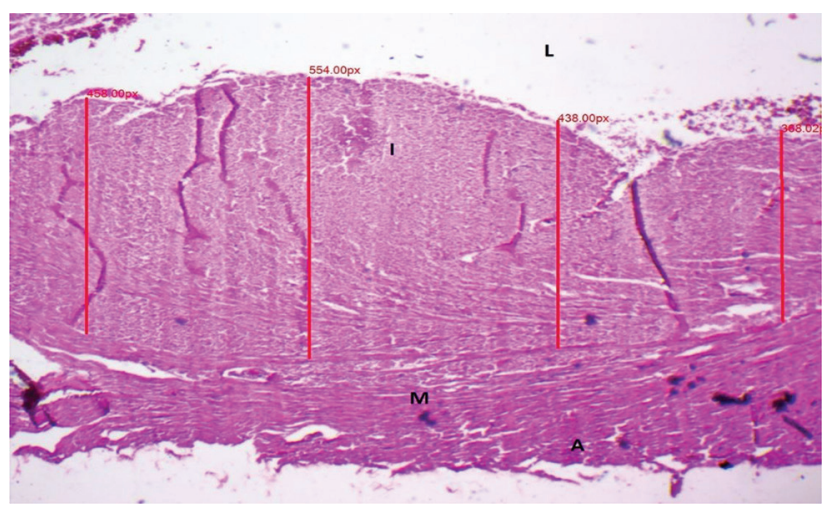

Fig. 2 Photomicrograph of histomorphometric section in aortic arch of rabbits on hypercholeterolemic diet for 8 weeks (induced-untreated) show diffuse intimal thickening and in completely coalesced extracellular lipid underneath a layers of macrophages and smooth muscle cells. The section stained with hematoxylin and eosin (10X), where, I: intima of the aorta, M: media of the aorta, A: adventitia of the aorta and L: the lumen of the aorta.

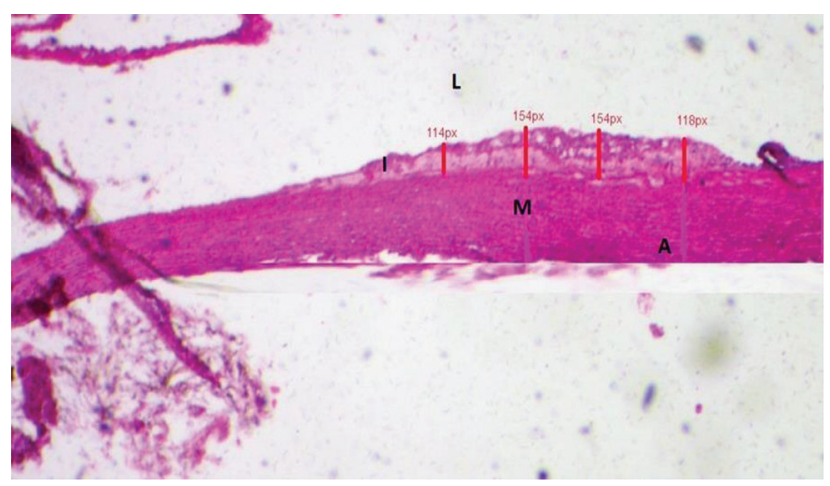

Fig. 3 Photomicrograph of histomorphometric section in aortic arch of Genistein hyperlipidemic rabbits. The section stained with hematoxylin and eosin (10X), where, I: intima of the aorta, M: media of the aorta, A: adventitia of the aorta and L: the lumen of the aorta.

serums after 56 days. Levels of HDL-C decreased significantly. Similar results were found by Prasad and Lee ${ }^{17}$ and Nigrisa and Paolo. ${ }^{18}$ Additionally, the outcomes of this investigation indicate a direct relationship between Genistein and the levels of serums TC, TG, HDL-C, LDL-C, VLDL-C, which agrees with the results 


$\begin{aligned} & \text { Table 4. Thickening values in aortic intima-media (px) after } \\
& \mathbf{5 6} \text { days. Values are represented as means } \pm \text { SEM (Six rabbits in } \\
& \text { each group) }\end{aligned}$
\begin{tabular}{lc} 
Group & Aortic intimal thickness $(\boldsymbol{\mu m})$ \\
\hline Normal control & $36.5 \pm 2.8$ \\
Dietary induced-untreated & $454.6 \pm 38.3^{*}$ \\
Genistein group & $135.0 \pm 11.0^{+}$
\end{tabular}

"Means for induced-untreated animals significant to control group.

${ }^{\dagger}$ Means for Genistein-treated animals significant to induced-untreated group.

of Eftekhari et al. ${ }^{19}$ and Tang et al. ${ }^{20}$ These results demonstrate that cholesterol levels lower when increasing LDL receptor activity, this increasing the absorption of LDL from the blood into the liver. Genistein reduces the activity of enzymes involved in fatty acid synthesis, such as fatty acid synthase, resulting in decreased serum triglyceride and VLDL. In terms of levels of hs-CRP, the results here agree with the results of $\mathrm{Zhao}$ and $\mathrm{Wu}{ }^{21}$ in that a remarkable increase was noted in levels of hs-CRP in comparison to rabbits on a normal diet. However, Genistein additives substantially decrease the hs-CRP plasma level in comparison to normal animals, these findings in line with Kim and Lim. ${ }^{22}$ Cholesterol-enriched diet caused significant increased levels of MCP-1 in comparison to control group, this in agreement with Chen et al. ${ }^{23}$ who showed that MCP-1 expression increased after a 3-week, high cholesterol diet in comparison to a control group. It has been proved that the MCP-1 plays an essential role in atherosclerosis disease, MCP-1 is expressed mainly through endothelial and inflammatory cells. The expression level is upregulated after tissue injury and proinflammatory stimuli, both correlating with atherosclerotic disease. ${ }^{24}$
The generation of MCP-1 substantially decreased in the Genistein treated animals, in comparison with the induced-untreated rabbits, this also in agreement with $\mathrm{Kim}$ and $\mathrm{Lim}^{22}$ who showed that a comparatively low amount of Genistein might decrease MCP-1 through suppression of NF- $\kappa$ B activation. In the current investigation, a clear increase was noted in levels of IL-6 in the hypercholesterolemic rabbits. This could be attributed to the fact that hypercholesterolaemia causes endothelial microinflammation, which increases the proinflammatory cytokine IL-6. These results are in agreement with those of Uich et al. ${ }^{25}$ and Elwakkad et al. ${ }^{26}$ In the current study, Genistein treatment caused a significant reduction of IL- 6 levels, this supported by Ibrahim et al. ${ }^{27}$ and Palanisamy et al. ${ }^{28}$ These collective results demonstrate that Genistein caused a substantial reduction in serum IL-6 in nonalcoholic steatohepatitis rats induced by a high fat diet (HFD). Genistein presents anti-inflammatory activity by reducing IKB- $\alpha$ phosphorylation in a nuclear factor kappa-light-chainenhancer of activated B cells (NF- $\mathrm{B}$ ) and inhibitor of kappa light polypeptide gene enhancer in B-cells (IKKB). In these studies, it was found that aortic intimal thickening and atherosclerosis area in hypercholesterolemic animals was substantially decreased by treatment with Genistein. Comparable outcomes were found by Wang et al. ${ }^{29}$

\section{Conclusion}

The findings of this investigation demonstrated that Genistein significantly decreased atherosclerosis progression in hypercholesterolemic rabbits via inhibition of inflammatory markers, reduced levels of lipid parameters.

\section{Conflict of Interest}

None.

\section{References}

1. Libby P, Ridker PM, Hansson GK. Progress and challenges in translating the biology of atherosclerosis. Nature. 2011;473:317-325.

2. Alexander RW, Dzau VJ. Vascular biology: the past 50 years. Circulation. 2000;102:IV112-IV116.

3. Banach M, Serban C, Sahebkar A, Mikhailidis DP, Ursoniu S, Ray KK et al. Impact of statin therapy on coronary plaque composition: a systematic review and meta-analysis of virtual histology intravascular ultrasound studies. BMC Med. 2015;13:229.

4. Collins R, Armitage J, Parish S, Sleigh P, Peto R, Heart Protection Study Collaborative Group. MRC/BHF Heart Protection Study of cholesterol-lowering with simvastatin in 5963 people with diabetes: a randomised placebo-controlled trial. Lancet. 2003 Jun 14:361:2005-2016.

5. Steffel J, Lüscher TF. Predicting the development of atherosclerosis. Circulation. 2009;119:919-921.

6. Aziz M, Yadav KS. Pathogenesis of Atherosclerosis. Med Clin Rev. 2016; 2:22.

7. Taketomi Y, Murakami M. Phospholipase A2 as a potential drug target for airway disorders. Obstructive Airway Diseases: Role of Lipid Mediators. 2016; Apr 19:41.

8. Corrado E, Rizzo M, Coppola G, Fattouch K, Novo G, Marturana I, et al. An update on the role of markers of inflammation in atherosclerosis. Atheroscler Thromb. 2010;17:1-11.

9. Shafi Dar M, Pandith AA, Sameer AS, Sultan M, Yousuf A, Mudassar S. hs-CRP: a potential marker for hypertension in Kashmiri population. Indian J Clin Biochem. 2010;25:208-212.

10. Rutter MK, Meigs JB, Sullivan LM, D'Agostino RB, Wilson PW. C-reactive protein, the metabolic syndrome, and prediction of cardiovascular events in the Framingham Offspring Study. Circulation. 2004;110:380-385.

11. Munro JM, Cotran RS. The pathogenesis of atherosclerosis: atherogenesis and inflammation. Lab Invest. 1988;58:249-261.
12. Gerszten RE, Garcia-Zepeda EA, Lim YC, Yoshida M, Ding HA, Gimbrone MA et al. MCP-1 and IL-8 trigger firm 184 adhesion of monocytes to vascular endothelium under flow conditions. Nature. 1999;398: 718-723.

13. Dewberry R, Holden $\mathrm{H}$, Crossman D, Francis S. Interleukin-1 receptor antagonist expression in human endothelial cells and atherosclerosis. Arterioscler Thromb Vasc Biol. 2000;20:2394-2400.

14. García DC, Valdecantos PA, Miceli DC, Roldán-Olarte M. Genistein affects proliferation and migration of bovine oviductal epithelial cells. Res Vet Sci. 2017;114:59-63.

15. Incir S, Bolayirli IM, Inan O, Aydın MS, Bilgin IA, Sayan I, et al. The effects of genistein supplementation on fructose induced insulin resistance, oxidative stress and inflammation. Life Sci. 2016;158:57-62.

16. Stary HC. Natural history and histological classification of atherosclerotic lesions: an update. Arterioscler Thromb Vasc Biol. 2000;20:1177-1178.

17. Prasad K, Lee P. Suppression of hypercholesterolemic atherosclerosis by pentoxifylline and its mechanism. Atherosclerosis. 2007;192:313-322

18. de Nigris F, Mancini FP, Balestrieri ML, Byrns R, Fiorito C, Williams-Ignarro S, et al. Therapeutic dose of nebivolol, a nitric oxide-releasing betablocker, reduce atherosclerosis in cholesterol-fed rabbits. Nitric Oxide. 2008; 19:57-63.

19. Eftekhari MH, Honarvar NM, Rajaeefard A, Owji A. Effect of daidzein and genistein on serum glucose, lipid profile and paroxonase activity in diabetic rats. Curr Top Nutraceutical Res. 2014;12:85-90.

20. Tang C, Zhang K, Zhao Q, Zhang J, Effects of dietary genistein on plasma and liver lipids, hepatic gene expression, and plasma metabolic profiles of hamsters with diet-induced hyperlipidemia. J Agric Food Chem. 2015;63:7929-7936.

21. Zhao SP, Wu ZH. Atorvastatin reduces serum leptin concentration in hypercholesterolemic rabbits. Clin Chim Acta. 2005;360:133-140. 
22. Kim MJ, Lim Y. Protective effect of short-term genistein supplementation on the early stage in diabetes-induced renal damage. Mediators Inflamm. 2013;2013:510212

23. Chen YL, Chang YJ, Jiang MJ. Monocyte chemotactic protein-1 gene and protein expression in atherogenesis of hypercholesterolemic rabbits. Atherosclerosis. 1999;143:115-123.

24. Lin J, Kakkar V, Lu X. Impact of MCP-1 in atherosclerosis. Curr Pharm Des. 2014:20:4580-4588.

25. Ikeda U, Ikeda M, Seino Y, Takahashi M, Kano S, Shimada K. Interleukin 6 gene transcripts are expressed in atherosclerosis lesion of genetically hyperlipidemic rabbits. Atherosclerosis. 1992;92:213-218
26. Elwakkad AS, Mohamed SI, Fathalla M. Relation between hypercholesterolaemia and vascular endothelial microinflammation. East Mediterr Health J. 2007;13:515-521.

27. Ibrahim AS, El-Shishtawy MM, Peña A, Liou GI. Genistein attenuates retinal inflammation associated with diabetes by targeting of microglial activation. Mol Vis. 2010;16:2033-2042.

28. Palanisamy N, Kannappan S, Anuradha CV. Genistein modulates NF-KBassociated renal inflammation, fibrosis and podocyte abnormalities in fructose-fed rats. Eur J Pharmacol. 2011;667:355-364.

29. Wang Y, Chun OK, Song WO. Plasma and dietary antioxidant status as cardiovascular disease risk factors: a review of human studies. Nutrients. 2013;5:2969-3004.

This work is licensed under a Creative Commons Attribution-NonCommercial 3.0 Unported License which allows users to read, copy, distribute and make derivative works for non-commercial purposes from the material, as long as the author of the original work is cited properly. 